\title{
A articulação da temática da doação de sangue e o ensino de biologia no Ensino Médio: uma pesquisa baseada em design
}

\section{The articulation between the theme of blood donation and biology teaching in middle school: a design based research project}

Leylane Porto Bittencourt ${ }^{1}$ • Miriam Struchiner ${ }^{1}$

\begin{abstract}
Resumo: Este estudo constituiu uma Pesquisa baseada em Design (PBD) que teve como objetivo analisar a articulação da temática da doação de sangue e o ensino de Biologia na perspectiva Ciência, Tecnologia e Sociedade (CTS). A pesquisa foi realizada em uma escola federal do Rio de Janeiro e envolveu professores do setor de Biologia e 18 estudantes do terceiro ano do Ensino Médio. Seguiu as fases da PBD: (1) análise do problema educativo; (2) desenvolvimento do artefato pedagógico; (3) intervenção e avaliação; (4) reflexão para produzir princípios de design. Como resultados, verificou-se que os professores influenciaram na compreensão do problema educativo e seu encaminhamento na pesquisa. No desenvolvimento, a professora se deparou com desafios práticos para incorporação da tecnologia no contexto pedagógico. $\mathrm{Na}$ intervenção, a professora e estudantes avaliaram positivamente o uso da tecnologia, sobretudo no que se referiu à articulação da temática da doação de sangue ao ensino de Biologia.
\end{abstract}

Palavras-chave: Pesquisa baseada em design. Ensino de biologia. Doação de sangue. Ciência, tecnologia e sociedade. CTS.

Abstract: This study was a Design Based Research (DBR) project that aimed to examine the articulation of the theme of blood donation and Biology Teaching from the perspective of STS. The locus of the study was a federal school in Rio de Janeiro and involved teachers from the Biology department and 18 third year middle school students. The development DBR stages were: (1) analysis of the educational problem; (2) development of educational artifact; (3) assessment and intervention, and (4) reflection to produce design principles. Results indicated that teachers influenced the understanding of the educational problem and the research process. During the development phase, the teachers faced practical challenges related to the incorporation of technology in the pedagogical context. In the intervention phase, teacher and students evaluated positively the use of technology, especially when it referred to the articulation of the theme of blood donation to the teaching of Biology.

Keywords: Design based research. Biology teaching. Blood donation. Science, technology, and society. STS.

\footnotetext{
${ }^{1}$ Núcleo de Tecnologia Educacional para a Saúde (NUTES), Universidade Federal do Rio de Janeiro (UFRJ). Rua Ituverava, n. 865, Jacarepaguá, CEP 22750-006, Rio de Janeiro, RJ, Brasil. E-mail: <leyporto@gmail.com>
} 


\section{Introdução}

A grande lacuna que existe na relação entre Ensino de Ciências (EC), o cotidiano e a vida sociocultural dos estudantes e de sua comunidade já vem sendo discutida por vários autores, que enfatizam que a abordagem tradicional, de natureza conteudista, tende a mistificar a neutralidade da ciência e a afastar o conhecimento científico e tecnológico da sociedade em geral, além de ignorar a responsabilidade política do mesmo (AULER, 2003; BAZZO et al., 2003; PINHEIRO; SILVEIRA; BAZZO, 2007; SANTOS, 2008).

Bazzo (1998) afirma que o cidadão, para poder participar nas decisões de ordem política e social que influenciarão o seu futuro e o dos seus filhos, precisa ser capaz de compreender os avanços da ciência e da tecnologia, com suas implicações para a sociedade. Neste sentido, entende-se que, para a leitura crítica da realidade, torna-se fundamental, cada vez mais, uma compreensão sobre as interações entre Ciência, Tecnologia e Sociedade (CTS), considerando que a dinâmica social contemporânea está fortemente condicionada pelo desenvolvimento científico-tecnológico (AULER; DELIZOICOV, 2006).

É nesse contexto que o movimento CTS tem mobilizado a atenção de pesquisadores de EC, que têm questionado o currículo praticado e investigado novas abordagens nas práticas pedagógicas (AULER, 2003; AULER; DELIZOICOV, 2001; SANTOS; MORTIMER, 2002). As propostas educacionais CTS são uma resposta à necessidade de a escola formar cidadãos capazes de discutir e tomar decisões sobre questões de Ciência e Tecnologia (CT) (SANTOS; MORTIMER, 2002).

Essa proposta curricular corresponde à integração entre educação científica, tecnológica e social. Ou seja, os conteúdos científicos e tecnológicos são estudados em suas dimensões histórica, ética, política e socioeconômica, tendo como meta principal preparar os estudantes para uma abordagem crítica e reflexiva sobre sua aprendizagem e para o exercício da cidadania (SANTOS, 2007; SANTOS; MORTIMER, 2001). Isso implica despertar, no estudante, seu papel na sociedade, sobretudo no que se refere ao compromisso de cooperação e corresponsabilidade social, na busca conjunta de solução para os problemas existentes.

Com isso, os objetivos propostos pelo CTS também incorporam os valores humanos, sobretudo os de interesse coletivo, como: solidariedade, fraternidade, compromisso social, reciprocidade, respeito ao próximo e generosidade (SANTOS, 2007; SANTOS; MORTIMER, 2002; SANTOS; SCHNETZLER, 1997). Pelo motivo de estar alicerçado na relevância social, Aikenhead (2006) chamou essa proposta como CTS humanístico, visto que o pensar humanístico ocorre quando o comprometimento social que se pretende é direcionado aos valores humanos.

Todos esses valores são importantes para o desenvolvimento da temática da doação de sangue, em qualquer instância, sobretudo na educação. A doação de sangue envolve questões científico-sociais e culturais que configuram uma problemática na saúde pública brasileira, especialmente porque aproximadamente $1,9 \%$ da população brasileira doa sangue. Esta taxa, de acordo com a Organização Mundial de Saúde, deve se manter entre 1,5\% a 3\% de doadores que doam regularmente para suprir os estoques e as necessidades dos pacientes (BACELAR, 2011). Portanto, é de suma importância a veiculação de informações sobre a necessidade de doações de sangue constantes, visto que a validade do sangue doado é de apenas 35 dias corridos (BRASIL, 2011).

Estas questões, quando incorporadas ao processo educativo, podem impactar no aumento de responsabilidade social dos estudantes para o ato da doação de sangue, e consequente 
solidariedade, sentido de humanidade e exercício da cidadania. Assim, a disciplina que facilita a abordagem dessa temática no contexto educacional é a de Biologia do Ensino Médio, por tratar de questões como: circulação, componentes e função das células e tipos sanguíneos.

O objeto de estudo deste trabalho foi pesquisar e analisar a articulação da educação em saúde, por meio da temática da doação de sangue, com as atividades curriculares da disciplina de Biologia do Ensino Médio, na perspectiva do CTS humanístico.

Como meio para essa articulação, a pesquisa envolveu o desenvolvimento de um material educativo mediado pelo uso de Tecnologias de Informação e Comunicação (TIC), isto é um Ambiente Virtual de Aprendizagem (AVA). O planejamento e a análise de sua implementação ocorreu no contexto da disciplina de Biologia no terceiro ano do Ensino Médio de uma escola pública federal.

Struchiner e Giannella $(2005,2006)$ ressaltam que as TICs oferecem um campo fértil de exploração na busca pela consolidação de currículos mais flexíveis, adaptados às características de aprendizagem dos estudantes, que permitem explorar novas experiências de aprendizagem. Além disso, viabilizam novas formas de organização das atividades pedagógicas e curriculares, oferecendo recursos que podem ser aplicados em sala de aula para enriquecer as experiências de aprendizagem dos estudantes e apoiar o ensino de conceitos científicos de difícil compreensão e visualização.

Esta pesquisa apoiou-se na abordagem metodológica de Pesquisa Baseada em Design (DESIGN-BASED RESEARCH COLLECTIVE, 2003; STRUCHINER, 2009; WANG; HANAFFIN, 2005) para desenvolver recursos e conhecimentos que possibilitem avançar na articulação de temáticas de relevância social como é o caso da doação de sangue com o ensino de Biologia, com o uso de TIC.

\section{A pesquisa baseada em design como percurso teórico-metodológico}

Segundo Wang e Hannafin (2005), a metodologia de Pesquisa Baseada em Design (PBD), do inglês Design Based Research (DBR), foi proposta, inicialmente, por Brown (1992) e Collins (1992). No entanto, sua difusão e produção acadêmica se desenvolveram, especialmente, nos últimos dez anos, uma vez que sua abordagem vem sendo integrada como uma perspectiva alternativa a modelos tradicionais (experimentais e quasi experimentais) de estudos sobre inovações pedagógicas em práticas educativas.

A PBD é uma abordagem interdisciplinar que tem como fundamento básico a natureza aplicada da pesquisa educacional (STRUCHINER, 2009). Assume, também, que fenômenos como aprendizagem, cognição e conhecimento não podem ser tratados como processos isolados do contexto e dos sujeitos em que se desenvolvem. Desta forma, propõe aliar pesquisa e práticas pedagógicas inovadoras, potencializando o conhecimento sobre o processo ensino -aprendizagem e contribuindo para a sua melhoria, por meio da parceria entre pesquisadores em educação, professores e estudantes em contextos reais de aprendizagem.

A busca por criar novas situações e investigar novas possibilidades de aprendizagem em contextos reais de aprendizagem define o principal objeto da PBD. A PBD é caracterizada: pelo foco nos problemas educativos complexos situados em contextos naturais de ensino-aprendizagem; pelo desenvolvimento de experiências/intervenções educativas onde se incluem, também, aquelas com o uso das Tecnologias de Informação e Comunicação (TIC), 
para contribuir na solução desses problemas; pela integração de teorias educacionais (teorias norteadoras), tanto para compreender os problemas quanto para desenvolver a experiência pedagógica; pelo desenvolvimento de intervenções a partir de um processo cíclico de análise, desenvolvimento, avaliação e (re)design; e pela construção de conhecimentos a respeito dos processos de desenvolvimento e de ensino-aprendizagem proporcionado pela intervenção (REEVES, 2000; WANG; HANNAFIN, 2005).

Investigações ancoradas nestes pressupostos incluem: o desenvolvimento de ferramentas e materiais baseados em TIC, estratégias de aprendizagem, currículo e, especialmente, de teorias que são usadas para compreender e dar suporte à aprendizagem (BARAB; SQUIRE, 2004; RAMOS, 2010). Portanto, esta metodologia se caracteriza não apenas pela intervenção, mas por sua característica peculiar de que estas intervenções incorporam reivindicações teóricas específicas sobre ensinar e aprender, e refletem um compromisso de estabelecer as relações entre teoria, artefatos projetados (podem ser materiais ou simbólicos) e a prática educativa (STRUCHINER, 2009). Assim, a PBD configura-se como um possível caminho a ser explorado em um campo de estudos que visa sistematizar e analisar como as ferramentas informacionais e comunicacionais podem ser apropriadas no processo educativo.

Reeves (2000) delineou o processo da PBD em quatro fases, que serviram de base para o presente estudo: a investigação parte de problemas educativos analisados com os sujeitos envolvidos nas práticas pedagógicas (fase 1); o artefato ou processo pedagógico é desenvolvido a partir da teoria norteadora, levando-se em conta as especificidades dos contextos (fase 2); a intervenção é considerada uma forma de compreender e avaliar como o artefato desenvolvido contribuiu na prática para a solução do problema educativo (fase 3); a partir da avaliação da intervenção, princípios de design são desenvolvidos sobre o processo de aprendizagem potencializado pelo artefato, permitindo revisitar cada fase do processo, refinar a intervenção e gerar conhecimentos sobre os pressupostos e teorias adotados (fase 4).

No presente estudo, ao mesmo tempo em que a PBD é o aporte metodológico utilizado no desenvolvimento do artefato pedagógico é, também, o eixo norteador da análise do processo.

\section{Contexto e sujeitos da pesquisa}

O presente estudo foi desenvolvido no setor de Biologia do Colégio de Aplicação (CAp) da Universidade Federal do Rio de Janeiro (UFRJ), que reúne sete professores licenciados em Biologia, que se alternam no ensino dos seguintes segmentos: quatro de Ciências no Ensino Fundamental $\left(6^{\circ}, 7^{\circ}, 8^{\circ}\right.$ e $9^{\circ}$ ano $)$ e três de Biologia $\left(1^{\circ}, 2^{\circ}\right.$ e $3^{\circ}$ ano $)$ no Ensino Médio.

Inicialmente, a pesquisa foi realizada com seis professores, pois um deles se encontrava de licença. Posteriormente, a professora coordenadora do setor, identificada no estudo como P6, se interessou em participar de todas as etapas da pesquisa, desenvolvendo material educativo e integrando a temática da doação de sangue em suas atividades de ensino, com 18 estudantes de uma das suas turmas do terceiro ano do Ensino Médio, no decorrer da disciplina de Biologia. 


\section{Produção e análise dos dados}

Como anteriormente mencionado, a pesquisa adotou a abordagem da Pesquisa Baseada em Design (DESIGN-BASED RESEARCH COLLECTIVE, 2003), e seus procedimentos se organizaram nas quatro fases da PBD, propostas por Reeves (2000).

\section{Fase 1 - Análise do problema educativo}

Esta fase foi realizada por meio de entrevistas com os professores do setor de Biologia CAp/UFRJ, com o intuito de identificar suas abordagens sobre questões relativas às temáticas sociais, à doação de sangue e às TICs em sala de aula. Após este contato inicial com os professores de Biologia, foram realizadas reuniões com a P6, que seguiu todas as fases da pesquisa. Concomitantemente, foram realizados seis momentos de observação participante, na qual a pesquisadora acompanhou as aulas de Genética ministradas por P6.

A partir da análise de conteúdo (BARDIN, 2011) das transcrições das reuniões com a P6, foi possível definir e elaborar mais detalhadamente o problema e definir as teorias de aprendizagem que sustentaram o processo da PBD.

\section{Fase 2 - Desenvolvimento do artefato pedagógico}

Esta fase envolveu o desenvolvimento do artefato pedagógico, com o uso da ferramenta Constructore ${ }^{2}$, para autoria de materiais e ambientes de aprendizagem na Internet. Esta ferramenta foi criada no Laboratório de Tecnologias Cognitivas (LTC) da UFRJ e possibilita a criação, publicação, edição e gerenciamento de materiais e atividades de aprendizagem pelo professor, sem necessidade de conhecimentos específicos de informática ou programação (STRUCHINER, 2009).

Esta etapa foi marcada por interações com a P6, no decorrer de sete reuniões, para reflexão e negociação sobre o conteúdo a ser desenvolvido na intervenção pedagógica, que resultou na construção do AVA denominado "Doação de sangue e o Ensino de Biologia". Além disto, incluiu o planejamento conjunto das estratégias de implementação deste material na disciplina de Biologia. A transcrição das sete reuniões serviu de fonte de informação para a tomada de decisões e análise desta etapa.

\section{Fase 3 - Intervenção e avaliação}

Esta fase incluiu a utilização do AVA, elaborado em parceria com a P6, no contexto da disciplina de Biologia, e teve a duração de três tempos de cinquenta minutos de aula no decorrer de um mesmo dia. O acompanhamento e a descrição detalhada da intervenção realizaram-se por meio de observação participante em sala de aula.

A avaliação dos estudantes a respeito da atividade desenvolvida foi realizada na medida em que cada grupo concluía suas atividades no AVA, por meio de entrevista semiestruturada

\footnotetext{
${ }^{2}$ Disponível em: <http://ltc.nutes.ufrj.br/constructore>. Acesso em: 01 out. 2014.
} 
com a pesquisadora. Posteriormente, realizou entrevista, também, com a P6, para compreender sua percepção sobre esta experiência com seus estudantes.

\section{Fase 4 - Análise retrospectiva para produzir princípios de design}

Ao final deste processo, foi realizada uma análise de todas as fases da pesquisa, utilizando-se, como fonte de informação, o material produzido durante todo o percurso da PBD: as gravações em áudio das entrevistas com os professores do setor de Biologia do CAp/UFRJ, o planejamento da aula interativa com a P6, a observação participante, e as entrevistas de avaliação da intervenção pelos estudantes e pela professora. Desta forma, analisou-se todo este primeiro ciclo de pesquisa e desenvolvimento.

\section{Aspectos Éticos da Pesquisa}

As condutas das pesquisadoras foram norteadas pela Resolução no 196/96 do Conselho Nacional de Saúde, que propõe diretrizes e normas que regulamentam as pesquisas envolvendo seres humanos (BRASIL, 1996). O projeto de pesquisa foi encaminhado à avaliação pelo Comitê de Ética em Pesquisa do Hospital Universitário Clementino Fraga Filho da UFRJ, tendo como protocolo de aprovação o número 031/11.

\section{Resultados e discussões}

\section{Fase 1 - Análise do problema educativo}

Seguindo a abordagem da PBD, o projeto iniciou com o contato estabelecido com os seis professores do setor de Biologia. Neste encontro, o grupo foi convidado a refletir sobre o problema educativo, elucidando a forma como os professores tratam as questões sociais no ensino. Eles declararam ser de suma importância aproximar o conteúdo programático das disciplinas com as vivências sociais dos estudantes, facilitando, assim, a apreensão de conceitos científicos de forma contextualizada. Com isso, em suas práticas, buscam ampliar a abordagem de ciência, discutindo aspectos para além da natureza da investigação científica e do significado dos conceitos científicos, aproximando-se das propostas curriculares baseadas na abordagem CTS (AULER; BAZZO, 2001; BAZZO et al, 2003; SANTOS; MORTIMER, 2002).

\section{[...] Ao você desenvolver conhecimentos acadêmicos, se você se aproximar mais da rea- lidade do estudante, você consegue fažer ele entender. Se você faz uma coisa totalmente distante, abstrata, sem fazer ligações com contextos sociais, ele não entende. [P5]}

Nesta etapa, foi possível perceber que a articulação da temática da doação de sangue nas disciplinas de ciências ou de Biologia ainda não tinha sido desenvolvida pela totalidade dos professores do grupo. Porém, todos concordaram com sua relevância e identificaram três momentos em que esta poderia ser incorporada no currículo. 
A doação de sangue abre um leque de possibilidades de articulação com ciências e a Biologia, no oitavo ano quando fala de corpo bumano, no segundo ano do ensino médio quando fala de circulação e no terceiro ano com a genética. [P4]

Os professores demonstraram, também, preocupação com as limitações da infraestrutura tecnológica da escola (equipamentos e conexão com a Internet) e com a pouca familiaridade dos docentes, em geral, com o uso pedagógico das TIC.

Eu sempre acho que a tecnologia é um treinamento. [...] Especialmente a primeira vez que você vai fazerer essa transposição, é bem difícil se você não está familiarizada com a ferramenta. [P2]

Todos os professores relataram que suas experiências com estes recursos resumiamse ao uso de imagens e vídeos para ilustrar conceitos científicos em contextos de sala de aula. Porém, este desafio foi minimizado quando a pesquisadora detalhou a proposta de parceria, que contemplava sua participação integral, inclusive no apoio ao desenvolvimento e implementação dos recursos de TIC.

A segunda etapa da análise do problema educativo se iniciou quando esta proposta de pesquisa consolidou-se na parceria com a P6, que se envolveu em todo o processo da PBD. Este momento foi importante para reafirmar, juntamente com a professora, o objetivo principal desta iniciativa. Ou seja, a articulação do ensino de Biologia com doação de sangue ocorreria com a aprendizagem de conceitos científicos relacionados a questões sanguíneas, que já são conteúdos abordados na disciplina.

Porque uma coisa é você discutir sobre a doação de sangue, outra coisa é eles pensarem que estão se formando na escola, que estão saindo da escola para o mundo. $\mathrm{Na}$ verdade, o nosso objetivo é maior que esse (sobre a articulação), a intenção é também estar buscando formar doadores conscientes. [P6]

Nas reuniões com a $\mathrm{P} 6$, foram apontados os conteúdos curriculares relacionados à proposta da intervenção pedagógica. Os conceitos de aglutinação das hemácias do sangue e reação antígeno e anticorpo compõem a temática de herança dos grupos sanguíneos no conteúdo de Genética da disciplina de Biologia do Ensino Médio. As aulas de Biologia, mais especificamente Genética, têm seus conteúdos orientados a partir das novas orientações curriculares para o Ensino Médio (BRASIL, 2006, p. 24), com a seguinte diretriz: “O estudante deve compreender como as informações genéticas codificadas no DNA definem a estrutura e o funcionamento das células e determinam as características dos organismos."

A definição da teoria de aprendizagem norteadora desta PBD ocorreu por meio de intensa negociação entre a professora e a pesquisadora. Foram levadas em conta - além da abordagem CTS humanístico (AIKENHEAD, 2006) do conteúdo curricular - as observações participantes realizadas na turma do terceiro ano do Ensino Médio, para se conhecer o estilo de trabalho da professora e de seu grupo de estudantes.

Foi possível constatar que a abordagem pedagógica da professora era pautada no diálogo e que suas atividades centravam-se na resolução de estudos dirigidos pelos estudantes. Esta abordagem oferecia um ambiente de sala de aula em que os estudantes expressavam 
ideias e opiniões, debatiam, trabalhavam com seus colegas, e eram estimulados a avançar nas suas aprendizagens. Pode-se afirmar, portanto, que a professora, mesmo sem uma formulação explícita, abraçava uma abordagem construtivista social (VIGOTSKY, 2001) em suas práticas de ensino de Biologia.

Tendo em vista que esta perspectiva era compatível com a visão da pesquisadora e de sua proposta de integrar a abordagem CTS educacional, o construtivismo social e a aprendizagem colaborativa foram as bases teórico-metodológicas que orientaram esta PBD. A base da aprendizagem colaborativa está na interação e troca entre os estudantes, com o intuito de adquirir novos conhecimentos (LEITE et al., 2005). Porém, não é a configuração de grupo que caracteriza a aprendizagem colaborativa, e sim a forma com que estudantes e professores trabalham em conjunto.

A gente tem um pensamento em comum na equipe de Biologia, que é esse, que é não ser conteudista, trabalhar temas que busquem o raciocínio do estudante, que busquem um pensamento. Eles levantarem questões e eles pensarem na solução, e em relação ao científico, utilizando uma linguagem mais adequada a eles. Não utilizamos os livros didáticos, que fica de consulta para eles, usamos materiais didáticos que nós mesmos fazemos, os estudos dirigidos. [P6]

Assim, tendo o construtivismo como base, optou-se pela abordagem da Teoria da Aprendizagem Significativa (TSA) (AUSUBEL; NOVAK; HANESIAN, 1980; MOREIRA, 1997) na perspectiva humanística de Novak (MOREIRA, 1997). Para Moreira (1999), as teorias construtivistas, de modo geral, são teorias de aprendizagem, e não de ensino. Para ele, a teoria de Ausubel, uma reconhecida teoria de aprendizagem, oferece diretrizes, princípios e estratégias que auxiliam a prática de ensino voltada para a aprendizagem significativa. $\mathrm{O}$ autor considera, ainda, que há uma relação entre as ideias de Vigotsky (2001) sobre a internalização dos significados de instrumentos e signos, e o processo de aprendizagem significativa de Ausubel, em que o significado lógico dos recursos de aprendizagem adquirem significado psicológico para que o estudante construa seu conhecimento de forma significativa.

A TSA emergiu, portanto, como uma teoria prática para implementação do material educativo e do modelo de intervenção, tendo em vista que, para perseguirem o objetivo de articular os conteúdos curriculares com as discussões sobre a doação de sangue, necessariamente, os estudantes deveriam ter a oportunidade tanto de integrar novos conceitos científicos sobre anatomia humana e genética com conceitos já estudados em outros anos, e, ainda, articular estes conceitos científicos com experiências, conhecimentos e valores sociais e afetivos relacionados à doação de sangue.

\section{Fase 2 - Desenvolvimento do artefato pedagógico e planejamento da intervenção}

O desenvolvimento do artefato pedagógico e o planejamento de seu uso na disciplina de Biologia ocorreu durante sete reuniões entre a professora e a pesquisadora.

Seguindo os princípios das teorias norteadoras e levando em conta os conhecimentos prévios sobre a temática sobre circulação sanguínea, optou-se pelo método da aprendizagem baseada em casos (ABC) (BERBEL, 1998; SCHANK; CLEARY, 1995; STRUCHINER; GIAN- 
NELLA, 2005) para elaboração do artefato pedagógico. A importância pedagógica da adoção do modelo de ABC é possibilitar, aos estudantes, não somente a solução de problemas, mas, sobretudo, desenvolver uma postura questionadora e a busca de informações que os auxiliem a definir e conceituar os problemas e buscar soluções compatíveis a cada nova situação.

Para Schank e Cleary (1995), a aprendizagem baseada em casos é muito comum na vida das pessoas, e o raciocínio envolvido neste processo é a forma predominante com a qual as pessoas pensam sobre o mundo em que vivem. Por exemplo, quando tomamos una decisão sobre o que fazer em uma determinada situação, nos baseamos, em geral, em registros de experiências anteriores (nossa ou de outros que servem de guias). Um ambiente de aprendizagem baseado em casos, segundo Riesbeck (1996), deveria ter as seguintes características: simular um mundo no qual os estudantes possam ter experiências; oferecer casos baseados em situações realistas; incluir papéis e tarefas claras para os estudantes, e possibilitar que os estudantes discutam e construam suas análises das situações, usando as informações disponíveis para apontar caminhos para a solução.

Assim sendo, definiu-se que os estudantes seriam convidados a participar de um cenário onde: (1) assumiriam o papel de "médicos" e enfrentariam a realidade da falta de sangue para atender a um paciente; (2) sensibilizados por esta situação, iriam doar sangue e passariam por todas as etapas da doação; (3) eles entrariam em contato com as duas realidades: bancos de sangue públicos e bancos de sangue privados.

Eu queria que eles primeiramente fossem médicos, que assim isso iria estar próximo da realidade deles, pois muitos querem fazer Medicina. Ao passarem pela falta de sangue, se sensibilizariam para doar. [...] Eles vão ver que no caminho do doador eles vão passar por alguns processos como a entrevista e testes no sangue. Vamos perguntá-los qual a importância disso tudo. [P6]

Desenvolveu-se, assim, um artefato pedagógico na ferramenta Constructore, que consiste na definição e implementação dos seguintes elementos do ambiente virtual de aprendizagem (AVA): (1) Informações sobre o curso; (2) Formulário de inscrição; (3) Recursos do curso; (4) Módulos do curso; (5) Escolha do layout, e (6) Liberação do curso.

O AVA desenvolvido, "Doação de Sangue e o Ensino de Biologia", foi estruturado em quatro módulos: Módulo 1 - "Sangue: artigo raro" apresenta uma situação-problema de uma paciente com necessidade de receber transfusão do tipo sanguíneo $\mathrm{O}$ negativo, que não foi atendida devido à falta de sangue. Neste módulo, os estudantes puderam rever conteúdos biológicos relacionados à função das células e tipos sanguíneos, quem doa pra quem; Módulo 2 - "Doação de sangue: caminho do doador" apresenta o percurso da doação de sangue, desde a identificação do doador, na recepção do serviço de coleta, até o lanche ao final. Este módulo elucidou conteúdos de circulação e volume sanguíneo corpóreo; Módulo 3 - "Refletindo sobre a doação de sangue" traz uma reflexão crítica sobre duas realidades brasileiras que envolvem a doação de sangue: os bancos de sangue públicos e privados. Neste módulo, os estudantes tiveram contato com questões históricas e econômicas relacionadas à doação de sangue, além de analisarem a forma de captação de doadores de sangue de cada realidade; Módulo 4 - "Avaliação da atividade", traz questões iniciais para os estudantes refletirem sobre a atividade que, depois, foram aprimoradas na entrevista com os grupos. Todos os módulos incluem recursos de aprendizagem (animações, imagens, textos, glossário e links úteis). Configurou-se, assim, um 
material educativo, que relacionou o ensino de Biologia com a Educação em Saúde, por meio da temática da doação de sangue, em seus aspectos conceituais, fisiológicos e socioculturais, distribuídos nos três primeiros módulos.

Planejou-se, ainda, como este artefato pedagógico seria integrado nas aulas de Biologia. Definiu-se que a atividade seria realizada em três tempos de aula seguidos e que os estudantes trabalhariam em grupos. Além disso, a professora integrou, ao planejamento da intervenção, a revisão da matéria e a introdução de novos conceitos relacionados à temática do sangue.

\section{Fase 3 - Intervenção e avaliação}

A intervenção ocorreu no final do ano letivo de 2011. Antes da intervenção com o uso do AVA propriamente dito, a professora trabalhou, com os estudantes, os conceitos sobre circulação e tipos sanguíneos, envolvidos no material, já que estes conteúdos fazem parte da grade curricular. Esta revisão teve a finalidade de servir como "organizador prévio" (AUSUBEL; NOVAK; HANESIAN, 1980) para os estudantes ativarem conhecimentos já trabalhados em aula e se prepararem para integrar os novos conceitos relacionados à doação de sangue, com o uso do AVA.

Participaram da atividade 18 estudantes, organizados em sete grupos: quatro trios e três duplas, que foram estabelecidos pelos próprios alunos no início da intervenção. A professora explicou, aos estudantes, os objetivos, apresentou o conjunto básico de informações teóricas a serem consultadas (estudos dirigidos das aulas de tipagem e circulação sanguínea), e indicou os problemas a serem resolvidos nos formulários elaborados para cada módulo. Além disso, ofereceu um panorama dos módulos, objetos de aprendizagem e formulários a serem consultados e/ou manipulados pelos estudantes na resolução do caso.

A professora, juntamente com a pesquisadora, acompanhou toda a atividade que foi realizada no laboratório de informática, ficando disponível para atender as dúvidas, propondo novas questões e realizando a discussão dos pontos essenciais. Os estudantes foram incentivados a explorar o material interativo conforme seu próprio interesse.

Os estudantes fizeram diversas perguntas, tanto sobre a manipulação da ferramenta Constructore quanto sobre questões de doação de sangue. O clima foi de ansiedade no início da manipulação da ferramenta Constructore; porém, com a informação da professora de que as orientações necessárias estariam explicitadas no decorrer de todo o percurso e, a partir dos primeiros contatos com o material, os estudantes compreenderam seu funcionamento e se concentraram rapidamente nas atividades do caso, respondendo às questões propostas nos formulários oferecidos no AVA.

O módulo no qual os estudantes apresentaram maior dificuldade foi o 2, "Doação de sangue: caminho do doador". Este módulo concretizava a articulação do conteúdo da disciplina de Biologia às questões científicas relacionadas à doação de sangue, especialmente na parte da triagem clínica-hematológica, momento no qual o doador é entrevistado pelo profissional de saúde e são feitos exames no doador para verificar se ele se encontra apto para realizar a doação de sangue, como: aferição da pressão arterial, temperatura, frequência cardíaca, a testagem de hemoglobina do doador, e a realização do grupo sanguíneo.

Mesmo com algumas dificuldades relacionadas à conexão da internet na escola, os estudantes participaram ativamente na resolução dos problemas, a partir do caso proposto para orientar a atividade. A motivação e participação ativa dos estudantes com a temática e com a 
atividade online ficaram evidentes no intenso debate que os grupos promoviam em sala, antes de responderem as perguntas a respeito da situação-problema apresentada.

\section{Avaliação dos grupos de estudantes e da professora}

A avaliação da aula pelos grupos foi positiva. Os estudantes não só articularam seus conhecimentos biológicos prévios com questões relacionadas à doação de sangue, como, também, demonstraram estar conscientes desta integração.

Foi bom que a gente testou nossos conbecimentos da matéria de Biologia dado no começo do ano e também por aproximar e incentivar a ir doar sangue. [G2]

Gostei muito, pois utilizamos o que vimos em sala de aula como teoria, porém numa situação criada. [G4]

Valorizaram, também, a temática da doação de sangue no ensino de Biologia, enfatizando a importância desta articulação, foco do presente trabalho.

Um jovem consciente [sobre a importância da doação de sangue]. Tem que crescer consciente [...] Porque nós somos o futuro. Os jovens são o futuro. Sempre serão. [G7]

É a melhor oportunidade das pessoas saírem daqui tendo uma informação. Informar melhor as pessoas. [...] o adulto não tem tanto contato com informação assim. [G5]

Em relação à articulação feita entre doação de sangue e a disciplina de Biologia, os grupos elencaram diferentes aspectos considerados relevantes, tais como: a simplicidade do ato de doar sangue; a necessidade de informar os estudantes sobre a doação de sangue no Ensino Fundamental e Médio, e a articulação dos conteúdos curriculares, tratados em sala de aula, com as questões sociais.

No que diz respeito ao uso do computador como meio para esta articulação, as falas dos grupos demonstraram a motivação dos estudantes com a inovação.

Porque a gente tem um ensino bem teórico na sala de aula. Então, eu acho que quando você vai para o site, com interatividade você aprende mais. [G7]

[...] saiu um pouco do comum de estar em sala de aula e tal... Mas sem deixar de estar aprendendo e revisando. [G6]

Assim, pode-se observar que os estudantes, em seus grupos de trabalho, em geral, consideraram a atividade desenvolvida positiva. Além disso, demonstraram facilidade no manuseio da ferramenta. Pode-se, também, perceber que a intervenção, como parte do processo desta PBD, cumpriu seu objetivo de favorecer a conscientização e a formação de uma atitude favorável à doação de sangue, além da articulação com os conteúdos de Biologia, na perspectiva CTS.

$\mathrm{Na}$ entrevista com a professora, ficou claro que, mesmo tendo passado por desafios com o uso da tecnologia e com a articulação da temática da doação de sangue com conteúdos 
de Biologia, a parceria com a pesquisadora auxiliou a superação das dificuldades iniciais, viabilizando crescimento pessoal e profissional.

Na verdade o que en ganhei mais com esse trabalho foi a oportunidade de conhecer, foi a discussão contigo. [...] esses conhecimentos eu nunca teria tido acesso se não fosse o contato com você e poder compartilhar isso com meus estudantes. [P6]

Entretanto, no processo de negociação entre a professora e a pesquisadora, foi possível destacar algumas dificuldades encontradas nessa forma de trabalho.

Você propor qualquer tema que integre várias coisas é muito mais difícil de ser feito [...] foram dificuldades que passamos ao construir um tema que articule as duas coisas. [...]. Então, en tive que aprender um monte de coisas, filtrar e tentar adapta-las pra minhas aulas. [P6]

A professora ressaltou a facilidade demonstrada pelos estudantes no manuseio da ferramenta no momento da intervenção. Tal facilidade deve-se ao fato das TICs já integrarem seus cotidianos.

[...] achei que os estudantes se interessaram muito, mais do que eu esperava, porque é a ferramenta que eles estão acostumados a usar. [...] Sair da sala ou fazer um jogo, alguma coisa diferente de aula expositiva, eles se motivam. Foi uma aula que todo mundo participou. Eles estavam focados fazendo aquilo. [P6]

Além disso, percebeu que a temática da doação de sangue foi uma temática que integrou diversas áreas de interesse dos estudantes.

A primeira parte do estudo era uma coisa mais médica. Então o pessoal da área médica adorou. Estavam se sentindo como médicos. E a segunda parte, que era a discussão mais social, o pessoal das Ciências Humanas também gostou. Então, en acho que a gente conseguiu fazer uma coisa que agradou, que integrou matéria e interesses dos estudantes. Eles gostaram de fazer [...] [P6]

Assim, ela concluiu que o objetivo de articular os conceitos do ensino de Biologia com o contexto social da doação de sangue foi alcançado.

[...] a gente conseguiu o nosso objetivo de integrar as duas áreas, a gente conseguiu integrar com uma ferramenta que eles gostam que é o computador e a partir dai teve um resultado: sensibilizamos pra questão da doação de sangue. [P6]

Vale ressaltar que, como desdobramento da aula interativa "Doação de Sangue e o Ensino de Biologia", ocorreu a doação de sangue voluntária por parte de oito estudantes, que juntamente com a professora, se organizaram e foram ao Instituto Estadual de Hematologia Arthur de Siqueira Cavalcanti (HEMORIO), para efetivarem sua primeira doação de sangue. Mesmo não sendo este o foco principal da pesquisa, os estudantes se sensibilizaram para a 
prática da doação de sangue e eles mesmos tomaram a iniciativa.

O interessante foi que eles se organizaram para realizar a doação de sangue no HEMORIO. [...] Eles se sensibilizaram. Eles quiseram sair pra doar sangue. E eu fui junto com eles para registrar o momento e também efetivei a doação. [...] Assim sei que eles sairão daqui cidadãos mais informados com relaşão a esta temática. E nós fizemos parte disso. [P6]

Em relação ao uso de um recurso tecnológico, como a Constructore, a professora declarou que a temática poderia ter sido desenvolvida pelo método usual que adota em suas aulas, como é o caso do estudo dirigido. Assim, indicou que, mais do que tratar a temática na perspectiva CTS, o seu maior desafio foi o uso de TICs em sua prática educacional.

O maior desafio foi aprender a mexer na ferramenta Constructore. Com certeza. Eu acho que o que foi positivo pra mim, foi aprender a lidar com essa tecnologia. Caso eu pretenda usar essa ferramenta novamente, en já aprendi como mexer e posso usar ela outras vezes caso en queira. [PG]

Ao mesmo tempo que, para aprender a desenvolver aulas na ferramenta Constructore, foram necessários mais esforço e tempo de planejamento e elaboração da aula, havia a premência de conciliar esta demanda com o prazo do projeto de pesquisa e com os conteúdos das aulas a serem ministrados. Dessa forma, P6 elencou alguns desafios nesta etapa como: o grande tempo dedicado para a construção do material na plataforma e o pouco tempo que resultou para desenvolver a atividade propriamente dita com os estudantes.

Acho que a gente fica sempre pressionada pra trabalbar com a questão do tempo, vestibular, essas coisas [...] cada vez mais a gente como professora fica sabendo como é importante nos planejarmos. O planejamento é uma coisa muito importante e temos que ter tempo para isso. [PG]

Evidenciou, também, limitações relacionadas ao uso da tecnologia, da estrutura e do acesso dos estudantes no laboratório de informática.

Tiveram as limitações do espaço, do número de computadores. Mas eu acho que a gente conseguiu superar isso. [...] Eu já tinha falado que não ia querer colocar uma ferramenta virtual pros meus estudantes que não são todos que têm acesso. [P6].

A professora elencou algumas sugestões para melhor adequar a ferramenta para uso no Ensino Médio, como, por exemplo, a inserção de outras opções de formatos de perguntas no formulário. Ressaltou, ainda, a importância de a atividade ter sido em ambiente presencial, mesmo que mediada pelas TICs, uma vez que, de acordo com sua experiência, o estudante nesta faixa etária ainda está em formação e algumas questões ainda são resolvidas por meio do diálogo direto professor-estudante.

Dessa forma, é possível concluir que a intervenção pedagógica compreendeu não apenas a experiência em sala de aula, mas incluiu todo o processo, desde o primeiro momento, 
em que os professores vivenciaram a reflexão acerca do problema educativo, até a iniciativa da P6 em incorporar a temática da doação de sangue mediada pelas TICs no contexto pedagógico, envolvendo seus alunos.

\section{Considerações finais}

O presente trabalho visou integrar questões humanas e sociais relacionadas à saúde, especificamente sobre o tema da doação de sangue, com os conteúdos curriculares de Biologia. Neste sentido, com base nos princípios e etapas da pesquisa baseada em design, efetivou-se uma proposta de abordagem CTS humanístico, por meio da parceria com uma professora de Biologia do Ensino Médio, que possibilitou o desenvolvimento de um material educativo mediado pelas TICs e sua integração nas atividades curriculares regulares da disciplina Biologia em uma escola pública do Rio de Janeiro.

No que diz respeito à proposta da abordagem CTS humanístico, constatou-se a viabilidade e pertinência desta integração, sem qualquer prejuízo para o desenvolvimento curricular relacionado às questões sanguíneas. Pelo contrário, constatou-se a alta motivação, tanto da professora quanto dos seus alunos, por um enfoque integrado desta natureza. Segundo Santos (2007), os aspectos sociocientíficos podem ser desenvolvidos, em sala de aula, transversalmente aos conteúdos e seus conceitos científicos, propiciando, aos estudantes, a compreensão do mundo social em que estão inseridos. Para o autor, uma característica crítica da abordagem CTS, é o foco na condição existencial do estudante, onde o currículo escolar contribua para desvendar a condição humana. Estes princípios, portanto, convergem para as Orientações Curriculares para o Ensino Médio, que visam o desenvolvimento do estudante para a cidadania, para obter atitude crítica e de responsabilidade social, visando à tomada de decisões em suas vidas (BRASIL, 2006).

Com base nestes resultados, é possível não apenas vislumbrar outras temáticas relacionadas à saúde no ensino de Biologia, mas repensar o próprio conceito de Educação em Saúde na escola. Os programas voltados para a questão da Saúde chegam à escola de forma deslocada do cotidiano e do currículo e, em geral, por meio de intervenções do setor saúde, ora prescritivas e autoritárias, ora conteudistas, sem levar em conta os conhecimentos, interesses e os valores dos alunos. Assim, o movimento CTS na visão humanística constitui um referencial para a reformulação das bases tanto da educação científica como da Educação em Saúde, com implicações para o fazer pedagógico e a dinâmica da própria sala de aula, com a possibilidade de superação das práticas conservadoras que perpassam as atividades curriculares e extracurriculares (BAZZO, 2012; SANTOS, 2008).

A parceria entre a pesquisadora e a professora foi um processo construtivo para ambas, onde aprenderam, compartilhadamente, com a oportunidade de refletir sobre suas experiências e conhecimentos (SCHNETZLER, 2002) sobre: ensino e pesquisa em ensino de ciências, abordagens curriculares comprometidas com uma formação cidadã, práticas pedagógicas inovadoras com uso de TICs e, especialmente, sobre o processo de aprendizagem e a receptividade dos alunos, quando participam de atividades contextualizadas e articuladas de conhecimento científico que circula em nossa sociedade e no cotidiano destes jovens.

Barab et al. (2005) pontuam que a pesquisa que visa a incorporação de uma inovação na área educacional deve se adaptar às necessidades dos contextos nos quais elas ocorrem, já que cada contexto as desafia com um novo conjunto de: circunstâncias, personalidades, recursos, 
normas culturais, e outras variáveis que, direta e indiretamente, viabilizam a sua implementação. Neste sentido, a parceria que se estabeleceu entre a professora e a pesquisadora mostrou-se como um caminho essencial para viabilizar um estudo que envolveu professor e alunos em seus contextos e atividades naturais de aprendizagem na escola.

No que diz respeito à integração das TICs no processo educativo, foi possível observar, no presente estudo, uma situação diferenciada entre a percepção da professora e a de seus alunos. Apesar de a professora ter alcançado, por meio da parceria com a pesquisadora, superar os desafios de desenvolvimento e uso destes recursos em sua prática educativa, não houve reconhecimento do valor pedagógico deste recurso para a prática de ensino de Biologia a partir da abordagem do CTS.

Isto porque a professora considerou que tudo o que foi realizado no ambiente de aprendizagem poderia ter sido feito por métodos e recursos mais usuais. Neste ponto, é interessante notar que, muitas vezes, o professorado tem a expectativa de que o uso das TICs tornará o trabalho docente menos laborioso do que os métodos tradicionais, quando o que ocorre, especialmente nas primeiras experiências, é o contrário (BARAB et al., 2005). Já os alunos, mostraram-se motivados para o estudo com o uso das TICs, enfatizando: a autonomia, a flexibilidade, o trabalho colaborativo, a comunicação e o modelo de ensino diferenciado possibilitado nesta experiência (STRUCHINER; GIANNELLA, 2006).

Reeves, Herrington e Oliver (2005) argumentam em defesa da PBD, enfatizando a crítica aos paradigmas que vêm orientando os estudos tradicionais que se desenvolvem em condições de investigação "artificiais" (experimentais ou quasi experimentais), que não produzem resultados relevantes sobre a aprendizagem e que pouco contribuem para a melhoria da qualidade dos processos educativos. Em outras palavras, como aborda o Design-Based Research Collective (2003), pesquisa educacional isolada da prática não dá conta da influência dos contextos, da natureza complexa dos resultados e da falta de conhecimento sobre os fatores que influenciam estes resultados.

Assim, o presente estudo envolveu o primeiro ciclo de uma PBD, desenvolvida por e para a pesquisa educacional, e que enseja, em sua essência, a integração de pesquisa, de planejamento/desenvolvimento de experiências/ambientes educativos inovadores e de prática educativa.

\section{Referências}

AIKENHEAD, G. S. Science education for everyday life: evidence-based practice. New York: Teachers College Press: Columbia University, 2006.

AULER, D. Alfabetização científico-tecnológica: um novo paradigma? Ensaio: pesquisa em educação em ciências, Belo Horizonte, v. 1, n. 1, p. 1-16, 2003.

AULER, D.; BAZZO, W. A. Reflexões para a implementação do movimento CTS no contexto educacional brasileiro. Ciência \& Educação, Bauru, v. 7, n. 1, p. 1-13, 2001.

AULER, D.; DELIZOICOV, D. Alfabetização científico-tecnológica para quê? Ensaio: pesquisa em educação em ciências, Belo Horizonte, v. 3, n. 1, p. 1-13, 2001. 
; Ciência-tecnologia-sociedade: relações estabelecidas por professores de ciências. Revista Electrónica de Enseñanza de las Ciencias, Vigo, v. 5, n. 2, p. 337-355, 2006.

AUSUBEL, D. P.; NOVAK, J. D.; HANESIAN, H. Psicologia educacional. Rio de Janeiro: Interamericana, 1980.

BACELAR, I. Ministério lança campanha para atingir 4 milhões de doadores de sangue. Brasília, 2011. Disponível em: < http://portal.saude.gov.br/portal/aplicacoes/ noticias/default.cfm?pg=dspDetalheNoticia\&id_area=124\&CO_NOTICIA=12760>. Acesso em: 14 jul. 2012.

BARAB, S.; SQUIRE, K. Design-based research: putting a stake in the ground. The Journal of the Learning Sciences, Georgia, v. 13, n. 1, p. 1-14, 2004.

BARAB, S. et al. Making learning fun: Quest Atlantis, a game without guns. Educational Technology Research and Development, Oklahoma, v. 53, n. 1, p. 86-107, 2005.

BARDIN, L. Análise de conteúdo. Lisboa: 70, 2011.

BAZZO, W. A. Ciência, tecnologia e sociedade: e o contexto da educação tecnológica. Florianópolis: Ed. da UFSC, 1998.

- Cultura científica versus humanística: a CTS é o elo? Revista Iberoamericana de Educación, Madrid, n. 58, p. 61-79, 2012. Disponível em: < http://www.rieoei.org/rie58a03. pdf >. Acesso em: 01 out. 2014.

BAZZO, W. et al. (Ed.). Introdução aos estudos CTS (ciência, tecnologia e sociedade). Madrid: Organização dos Estados Ibero-americanos para a Educação, a Ciência e a Cultura, 2003.

BERBEL, N. N. A problematização interface e a aprendizagem baseada em problemas: diferentes termos ou diferentes caminhos? Interface: comunicação, saúde, educação, Botucatu, v. 2, n. 2, p. 139-154, 1998. Disponível em: < http://dx.doi.org/10.1590/S141432831998000100008>. Acesso em: 01 out. 2014.

BRASIL. Ministério da Educação. Secretaria de Educação Básica. Orientações curriculares para o ensino médio. Brasília, 2006.

- Ministério da Saúde. Conselho Nacional de Saúde. Normas de pesquisa envolvendo seres humanos. Res. CNS 196/96. Bioética, Brasília, v. 4, n. 2, p. 15-25, 1996. (Suplemento).

. Ministério da Saúde. Portaria n⿳0 1.353 , de 13 de junho de 2011. Aprova o regulamento técnico de procedimentos hemoterápicos. Brasília, 2011. Disponível em: <http://bvsms.saude.gov.br/bvs/saudelegis/gm/2011/prt1353_13_06_2011.html >. Acesso em: 01 out. 2014.

BROWN, A. L. Design experiments: theoretical and methodological challenges in creating complex interventions in classroom settings. The Journal of the Learning Sciences, Georgia, v. 2, n. 2, p. 141-178, 1992. 
O recurso à modelação no ensino das ciências: ...

COLLINS, A. Towards a design science of education. In: SCANLON, E.; O'SHEA, T. New directions in educational technology. Berlin: North Atlantic Treaty Organization, 1992. p. $15-22$.

DESIGN-BASED RESEARCH COLLECTIVE. Design-based research: an emerging paradigm for educational inquiry. Educational Researcher, Culver City, v. 32, n. 1, p. 5-8, 2003.

LEITE, C. L. K. et al. A aprendizagem colaborativa na educação a distância on-line. São Paulo: Associação Brasileira de Educação a Distância, 2005.

MOREIRA, M. A. Aprendizagem significativa. Brasília, Editora: UnB, 1999. . Aprendizagem significativa: um conceito subjacente. In: MOREIRA, M. A.; CABALLERO, M. C.; RODRÍGUEZ, M. L. (Org.). Actas del Encuentro Internacional sobre el Aprendizaje Significativo. Burgos: [s.n], 1997. p. 19-44. Disponível em: <http:// www.if.ufrgs.br/ $\sim$ moreira/apsigsubport.pdf >. Acesso em: 01 out. 2014.

PINHEIRO, N. A. M.; SILVEIRA, R. M. C. F.; BAZZO, W. A. Ciência, tecnologia e sociedade: a relevância do enfoque CTS para o contexto do ensino médio. Ciência $\boldsymbol{\&}$ Educação, Bauru, v. 13, n. 1, p. 71-84, 2007.

RAMOS, P. Ambiente virtual Vivências: análise do processo de desenvolvimento na perspectiva da pesquisa baseada em design. 2010. 240 f. Tese (Doutorado em Educação em Ciências e Saúde) - Núcleo de Tecnologia Educacional para a Saúde, Universidade Federal do Rio de Janeiro, Rio de Janeiro, 2010.

REEVES, T. C. Socially responsible educational technology research. Educational Technology, Englewood Cliffs, v. 40, n. 6, p. 19-28, nov./dez. 2000.

REEVES, T. C.; HERRINGTON, J.; OLIVER, R. Design research: a socially responsible approach to instructional technology research in higher education. Journal of Computing in Higher Education, New York, v. 16, n. 2, p. 96-116, 2005.

RIESBECK, C. Case-based teaching and constructivism: carpenters and tools. In: WILSON, B. G. (Ed.). Constructivist learning environments: case studies in instructional design. Englewood Cliffs: Educational Technology Publications, 1996. p. 49-61.

SANTOS, W. L. P. Contextualização no ensino de ciências por meio de temas CTS em uma perspectiva crítica. Ciência \& Ensino, Piracicaba, v. 1, p. 1-12, 2007. (Número especial).

Educação científica humanística em uma perspectiva freireana: resgatando a função do ensino de CTS. Alexandria: revista de educação em ciência e tecnologia, Florianópolis, v. 1, n. 1, p. 109-131, mar. 2008.

SANTOS, W. L. P.; MORTIMER, E. F. Uma análise de pressupostos teóricos da abordagem C-T-S (ciência-tecnologia-sociedade) no contexto da educação brasileira. Ensaio: pesquisa em educação em ciências, Belo Horizonte, v. 2, n. 2, p. 1-23, dez. 2002.

; _. Tomada de decisão para ação social responsável no ensino de ciências.

Ciência \& Educação, Bauru, v. 7, n. 1, p. 95-111, 2001. 
Bittencourt, L. P.; Struchiner, M.

SANTOS W. L. P.; SCHNETZLER, R. P. Educação em química: compromisso com a cidadania. Ijuí: Ed. Unijuí, 1997.

SCHANK, R. C.; CLEARY, C. Case-based teaching. In: SCHANK, R. C.; CLEARY, C. Engines for education. Hillsdale: Lawrence Erlbaum, 1995. p. 123-137.

SCHNETZLER, R. P. A pesquisa em ensino de química no Brasil: conquistas e perspectivas. Química Nova, São Paulo, v. 25, p. 14-24, 2002. (Suplemento).

STRUCHINER, M. Apreciação analítica de ambientes construtivistas de aprendizagem baseados em novas tecnologias de informação e de comunicação para a educação na área das ciências da saúde. Rio de Janeiro, 2009. (Projeto submetido ao CNPq, não publicado).

STRUCHINER, M.; GIANNELLA, T. R. Aprendizaje y práctica docente en el area de la salud: conceptos, paradigmas e innovaciones. Washington: OPS, 2005.

. Novas tecnologias de informação e comunicação na formação de recursos humanos em saúde. In: MONTEIRO, S.; VARGAS, E. (Org.). Educação, comunicação e tecnologia educacional: interfaces com o campo da saúde. Rio de Janeiro: Fiocruz, 2006. p. $129-140$.

VIGOTSKY, L. S. A formação social da mente. São Paulo: Martins Fontes, 2001.

WANG, F.; HANNAFIN, M. J. Design-based research and technology-enhanced learning environments. Educational Technology Research and Development, Oklahoma, v. 53, n. 4, p. 5-23, 2005. 